\title{
EXPRESSION AND IMMUNOGENICITY OF THE SPIKE GLYCOPROTEIN OF PORCINE RESPIRATORY CORONAVIRUS ENCODED IN THE E3 REGION OF ADENOVIRUS
}

\author{
P. Callebaut and M. Pensaert \\ Laboratory of Virology \\ Faculty of Veterinary Medicine \\ University of Gent \\ Casinoplein 24 \\ B-9000 Gent, Belgium
}

\begin{abstract}
The full length spike (S) gene of porcine respiratory coronavirus (PRCV) was inserted into the genome of human adenovirus type 5 downstream of the early transcription region 3 promoter. The recombinant virus replicated in cultures of the swine testicle ST cell line and directed the synthesis of S antigen to an amount of approximately $33 \mu \mathrm{g}$ per $10^{6}$ cells, as determined by ELISA. The antigen was cell-associated except in the late phase of the infection, when a low amount $\left(4 \mu \mathrm{g}\right.$ per $10^{6}$ cells $)$ was released in the culture supernatant. The cell-associated antigen consisted of 2 polypeptides of $160 \mathrm{~K}$ and $175 \mathrm{~K}$, respectively. The $160 \mathrm{~K}$ polypeptide comigrated with the authentic S' precursor from PRCV-infected cells. The $175 \mathrm{~K}$ polypeptide had the same mobility as the authentic mature $\mathrm{S}$ protein from PRCV-infected cells and from PRCV released in the supernatant. The extracellular recombinant antigen corresponded with the $175 \mathrm{~K}$ mature protein. Immunofluorescent staining gave evidence that some recombinant $\mathrm{S}$ protein was exposed on the cell surface; it also showed that the protein was recognized by conformation-specific anti-S monoclonal antibodies. Piglets, immunized oronasally with the recombinant adenovirus vector developed PRCV-neutralizing serum antibodies and were partially protected against PRCV - challenge.
\end{abstract}

\section{INTRODUCTION}

The use of human adenovirus type 5 (Ad5) for the construction of recombinant expression vectors is well established ${ }^{1}$. Previous work in our laboratory has shown that this 
virus causes a subclinical respiratory infection in swine ${ }^{2}$. Therefore, $\mathrm{Ad} 5$ is a candidate as a vaccine vector for the induction of an immune response in the porcine respiratory tract.

Porcine respiratory coronavirus (PRCV) can serve as a well known model suitable to study the vaccine potential of recombinant Ad5-based vectors. The major virus neutralization mediating antigenic sites are located on the spike (S) glycoprotein ${ }^{3,4}$. In PRCV-infected cells the $S$ protein is initially synthesized as a precursor species $S^{\prime}$ of 1255 amino acids. By posttranslational processing the mature $S$ protein is produced which is incorporated in the viral membrane ${ }^{5}$.

In the present communication we report the development of an infectious Ad vector (AdgpS) which carries the entire PRCV S gene in the early transcription region 3 (E3) of its genome and directs a high level expression in porcine cells. We also describe the biochemical and biological properties of the expressed product and demonstrate that the vector has immunogenic and protective potential in piglets.

\section{MATERIAL AND METHODS}

\section{Viruses and Cells}

The PRCV isolates TLM $83^{6}$ and $91 \mathrm{~V} 44^{7}$ were used as the source of viral genomic RNA and for challenge of piglets, respectively. Both isolates were grown in cultures of the swine testicle (ST) cell line. The same cell line was used for titration of PRCV from nasal swabs of piglets, for growth and titration of AdgpS and for Ad5 neutralization assays. DNA transfection was performed in the human embryonal cell line 293. Swine kidney (SK6) cells were used for PRCV/TGEV neutralization tests ${ }^{8}$.

\section{Construction of the Recombinant Vector}

The PRCV S gene insert was prepared starting from genomic RNA, extracted from purified PRCV virions, as described ${ }^{9}$. A cDNA was synthesized using the oligonucleotide primer 5'TCTGCTAGCTTAAATTTAATGGACGTGCAC; the Supercript Preamplification system (BRL) was used in the conditions prescribed by the manufacturer except for the incubation time with reverse transcriptase, which was $90 \mathrm{~min}$. The DNA was amplified by PCR using the above oligonucleotide and the oligonucleotide 5' TAGCTAGCCACACCATGAAAAAATTATTTG as $5^{\prime}$ and $3^{\prime}$ amplimers, respectively. Thirty cycles $\left(95^{\circ} \mathrm{C}\right.$ for $1 \mathrm{~min}$, $72^{\circ} \mathrm{C}$ for $15 \mathrm{~min}, 56^{\circ} \mathrm{C}$ for $2 \mathrm{~min}$ ) were performed with 5 units of Taq DNA polymerase (Perkin Elmer Cetus).

The recombinant adenovirus AdgpS was constructed according to the procedure of Graham and Prevec ${ }^{10}$. Plasmids $\mathrm{pFG} 144^{11}$ and $\mathrm{pFG173^{12 }}$ were kindly provided by L. Enjuanes (Centro Nacional de Biotecnologia, Spain). Transfection of 293 cells was performed using the calcium phosphate coprecipitation method ${ }^{13}$.

\section{Immunologic Assays}

To measure the level of expression by antigen-capture sandwich ELISA, cells were lysed in $0.05 \mathrm{M}$ Tris- $\mathrm{HCl} \mathrm{pH} 8,0.5 \mathrm{M} \mathrm{NaCl}, 1 \%$ Triton $\mathrm{X}-100,0.1 \%$ deoxycholate (lysis buffer). To improve detection of extracellular $\mathrm{S}$ antigen the culture supernatants were concentrated 10 -fold by dialysis against $20 \%$ polyethylene glycol 20000 (PEG) and subsequentely diluted $1 / 2$ in $2 x$ lysis buffer. The ELISA was performed essentially as described $^{14}$, using pig anti-TGEV IgG as the capture antibody and pig anti-TGEV horseradish peroxidase conjugate. Serial dilutions of samples were tested and ELISA absorbances 
were converted to S protein concentrations using a cell lysate with a known concentration of purified PRCV virions as a standard; the $\mathrm{S}$ protein content of this preparation was considered $1 / 4$ of the total viral protein.

For immunoblot analysis of recombinant $S$ protein, cells were lysed in $0.05 \mathrm{M}$ Tris-HCl, pH 8, 1\% SDS (gel-loading buffer). Cell culture supernatant was concentrated by dialysis against $20 \%$ PEG and subsequently diluted $1 / 2$ in $2 \mathrm{x}$ gel-loading buffer to give a final volume which was equal to that of the cell lysate. The proteins were resolved by electrophoresis on a $8 \%$ SDS-PAGE gel and were transferred onto nitrocellulose membrane (Bio-Rad) using a Bio-Rad Trans-Blot Cell. The membrane was probed with pig anti-TGEV serum and the reaction was developed using rabbit anti-pig IgG antibodies conjugated to horseradish peroxidase (Nordic).

Indirect immunofluorescence assays were performed using ST cell cultures, grown on glass coverslips and infected with AdgpS at a multiplicity of 10. After $24 \mathrm{~h}$ the cells were fixed in $0.1 \%$ paraformaldehyde for $30 \mathrm{~min}$ at $4{ }^{\circ} \mathrm{C}^{15}$ and probed with 2 pools of monoclonal antibodies (Mabs), each of which was directed against one of the antigenic sites A and D of the $\mathrm{S}$ protein. The MAbs were gifts of $\mathrm{L}$. Enjuanes and were diluted $1 / 100$. Bound antibody was detected with fluorescein -conjugated anti-mouse IgG antiserum (Nordic).

Serum PRCV neutralizing activity was measured by a microtiter virus neutralization (VN) assay described previously ${ }^{8}$. Ad5-neutralizing activity of the sera was detected by a similar microneutralization assay.

\section{Inoculation and Challenge of Piglets}

Four piglets of 4 weeks of age which were free of Ad5-neutralizing serum antibodies were obtained from a PRCV negative farm. Two of them were inoculated oronasally with each $2.5 \times 10^{10}$ median tissue culture infectious doses $\left(\mathrm{TCID}_{50}\right)$ of $\mathrm{AdgpS}$. The two remaining piglets were not inoculated and served as challenge controls. Challenge was performed four weeks after the AdgpS inoculation, using $10^{7} \mathrm{TCID}_{50}$ of PRCV per animal, administered via aerosol as described ${ }^{7}$. In order to study the antibody response to PRCV, serum samples were collected on the day of inoculation with AdgpS, on the day of challenge and on post-challenge days (PCD) 2, 4, 6, 8 and 10, and tested in the $\mathrm{VN}$ assay. To estimate the degree of protection against challenge, the shedding of PRCV was determined in nasal swabs collected daily from the day of challenge until PCD10. Infectious virus titers in the secretions were determined as described previously ${ }^{7}$.

\section{RESULTS AND DISCUSSION}

\section{Construction of the Recombinant Vector}

A full length DNA copy of the S gene coding sequence (from 6 nucleotides upstream to 3684 nucleotides downstream the initation codon) was obtained by reverse transcription of the viral genomic RNA, followed by PCR amplification. The amplimers were chosen to introduce a Nhe I site at each end, thus allowing cloning into the Ad5 transfer vector pFG144 ${ }^{11}$. In the resulting plasmid pFG144gpS the PRCV gene replaced the largely deleted E3 region which was previously shown to be nonessential for Ad5 replication ${ }^{2}$. The insert was oriented parallel to the direction of transcription of the E3 promoter. The recombinant Ad5-gpS sequences in plasmid pFG144gpS were rescued in the Ad5 genome following cotransfection of human 293 cells along with the overlapping Ad5 subgenomic plasmid pFG $173^{12}$ by homologous overlap recombination. 


\section{Expression in Porcine Cells in Culture}

The kinetics of the $\mathrm{S}$ expression as determined in cell lysates and culture supernatants of the porcine cell line ST by quantitative sandwich ELISA are shown in Fig.1. In the cell lysates the cumulative amount of recombinant $S$ antigen increased at the highest rate between 18 and $24 \mathrm{~h}$ post-inoculation. This was before the appearance of cytopathic effect and probably consistent with transcription driven by the E3 promoter. The maximum level of 33 $\mu \mathrm{g} / 10^{6}$ cells was produced at $48 \mathrm{~h}$ post-inoculation, when $50 \%$ of the cells showed cytopathic effect. In the culture supernatant $\mathrm{S}$ antigen was detectable starting at $48 \mathrm{~h}$ post-inoculation. Late in the infection, at $72 \mathrm{~h}$ post-inoculation when cytopathic effect was complete, the yield of extracellular S antigen was $4.4 \mu \mathrm{g} / 10^{6}$ cells.

Immunoblot analysis was performed to identify the recombinant protein in the ST cell lysate and culture supernatant at the terminal phase of the infection. The cell-associated protein and extracellular protein, produced by equal numbers of cells, were analysed. In the lysate 2 polypeptides of $160 \mathrm{~K}$ and $175 \mathrm{~K}$, respectively were identified (Fig. 2). The $160 \mathrm{~K}$ polypeptide was the predominant species and had the same mobility as the authentic precursor $\mathrm{S}^{\prime}$ protein present in PRCV-infected cell lysate but not in PRCV released in the medium. The minor $175 \mathrm{~K}$ polypeptide comigrated with the authentic mature $\mathrm{S}$ protein present in PRCV-infected cells as well as in extracellular PRCV. In the supernatant of AdgpS-infected cells the $175 \mathrm{~K}$ polypeptide was identified. These results indicated that the recombinant $\mathrm{S}$ is properly processed intracellularly. It was noted that late in the infection the majority of the processed protein is exported out of the cells.

Cells, fixed with paraformaldehyde and assayed by indirect immunofluorescence at $24 \mathrm{~h}$ after infection with AdgpS, showed membrane fluorescence when reacted with Mabs against antigenic sites $\mathrm{A}$ and $\mathrm{D}$ of the $\mathrm{S}$ protein. At that early time after infection it was unlikely that the appearance of cell surface fluorescence was caused by $S$ protein, released from the cells and subsequently bound back to cell surface receptors. Therefore, the immunofluorescence suggests that some recombinant $\mathrm{S}$ is transported to the cell surface. In addition, the reactivity with the Mabs indicates that the recombinant $S$ is folded in a conformation similar to that of the authentic protein and retains the important antigenic sites.

\section{Immunogenicity in Piglets}

Four weeks after the oronasal inoculation of 2 piglets with AdgpS, both piglets showed seroconversion against PRCV and against Ad5. The PRCV-neutralizing activity was

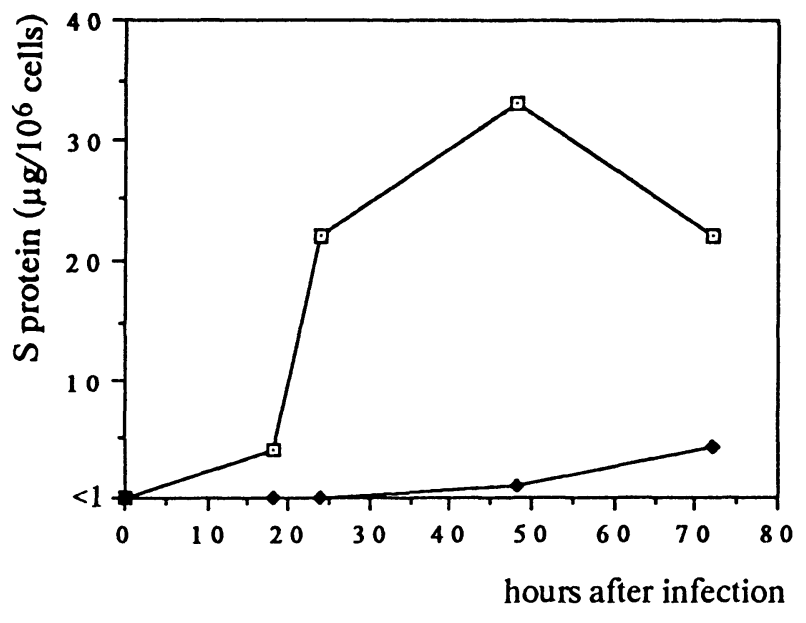

Figure 1. Kinetics of recombinant $S$ production in ST cells. Cells were inoculated with AdgpS at a multiplicity of 10 . At the indicated times post-infection cell extracts $(\square)$ and culture supernatants $(r)$ were assayed by antibody sandwich ELISA. The amounts of $S$ protein were expressed in $\mu \mathrm{g}$ per $10^{6}$ cells, calculated as described in Methods. 
Figure 2. Immunoblot analysis of recombinant $\mathrm{S}$ synthesized in ST cells. Cells were inoculated with AdgpS (lanes 2 and 5), with PRCV (lanes 1 and 4) and with Ad5 (lanes 3 and 6) at a multiplicity of 10 . At $72 \mathrm{~h}$ after infection with the adenoviruses and $48 \mathrm{~h}$ after infection with PRCV, cells were lysed (lanes 1 to 3 ) and culture supernatants (lanes 4 to 6) were concentrated as described in Methods. Following electrophoresis under nonreducing conditions, proteins were transferred to a nitrocellulose sheet and probed by anti-TGEV porcine serum. Precursor $S^{\prime}$ and mature $S$ polypeptides are indicated.

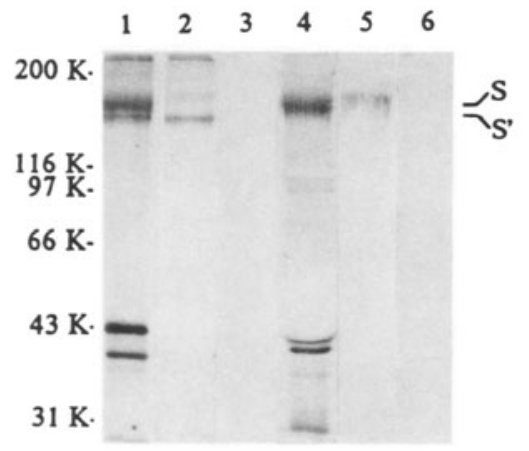

detected at titers of 4 and 12; the Ad5 VN-titers were 8 and 32, respectively. Two non-inoculated control piglets remained negative in the VN-tests.

Following challenge the AdgpS inoculated piglets responded by 6 days with a marked increase in their VN-titer, typical of an anamnestic response (Fig. 3.A). The controls showed a response typical of immunologically naive pigs. As indicated in Fig. 3.B, both AdgpS-inoculated piglets showed similar patterns of shedding of PRCV in nasal secretions; there was a marked reduction in the quantity and duration of virus excretion, compared to that of the control piglets.

In spite of the low number of animals studied, the finding that AdgpS elicited a low level of PRCV-neutralizing antibodies indicates that recombinant $\mathrm{S}$ protein was expressed in the pigs.

Figure 3. PRCV neutralizing antibody titers in serum (A) and PRCV-titers in nasal secretions $(B)$ at the indicated times after PRCV-challenge of 2 piglets, inoculated with AdgpS 4 weeks before challenge (-) and of 2 control piglets, not inoculated with AdgpS (-- -). PRCV titers are expressed in $\log _{10}$ median tissue culture infectious doses $\left(\mathrm{TCID}_{50}\right)$ per $100 \mathrm{mg}$ of secretion.

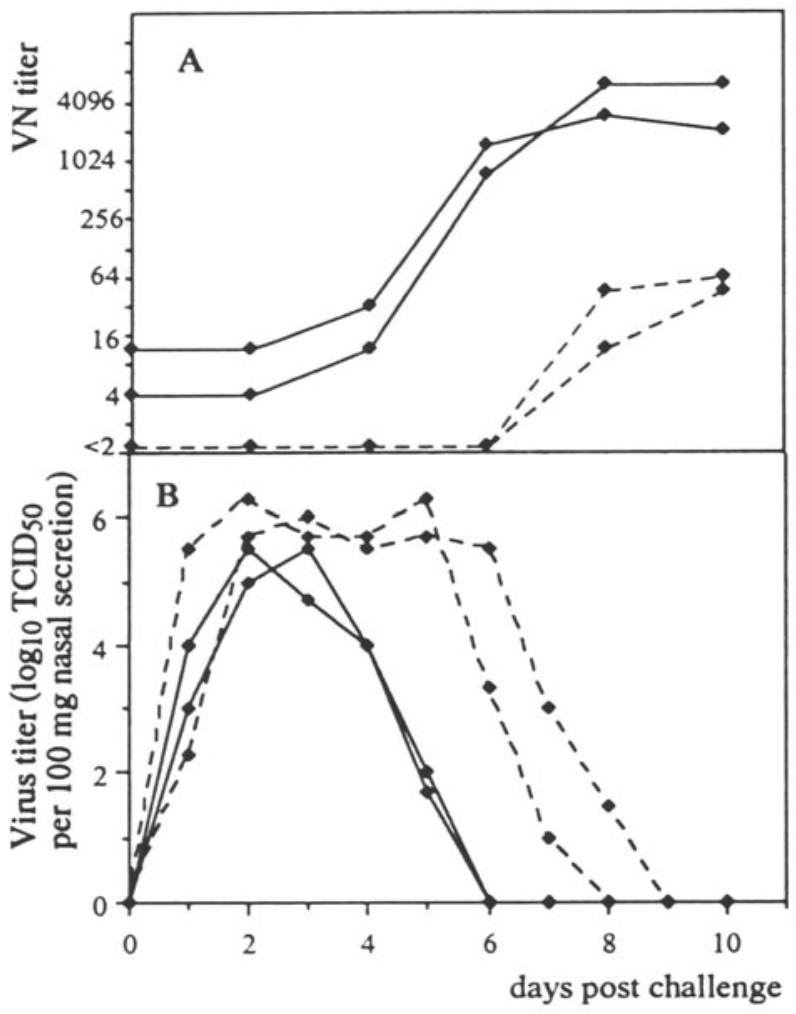


This is confirmed by the observed partial protection and boosted serum antibody response upon challenge. The present data suggest that the immune response induced in the pigs by the recombinant $S$ protein is boosted by the $S$ antigen produced in the initial rounds of replication of the challenge virus, resulting in the shortened duration of challenge virus shedding. Work is in progress to corroborate these results and to study the suitability of the AdgpS vector as a live vaccine.

\section{ACKNOWLEDGMENTS}

We thank Dr. K. Van Reeth for help with the animal experiments. This work was supported by the Institute for the Encouragement of Scientific Research in Industry and Agriculture, Brussels.

\section{REFERENCES}

1. Berkner, K.L. (1992). Curr. Top. Microbiol. Immunol. $158: 39$.

2. Callebaut, P., Pensaert, M. and Enjuanes, L. (1994). Adv. Exp. Med. Biol. $342: 469$.

3. Correa, I., Gebauer, F., Bullido, M.J., Suné, C., Baay, M.F.D., Zwaagstra, K.A., Posthumus, W.P.A., Lenstra, J.A. and Enjuanes, L.(1990). J. Gen. Virol. 71 : 271.

4. Delmas, B., Rasschaert, D., Godet, M. and Laude, H.(1990). J. Gen. Virol. 71 : 1313.

5. Rasschaert, D., Duarte, M. and Laude, H.(1990). J. Gen. Virol. $71: 2599$.

6. Pensaert, M., Callebaut, P. and Vergote, J.(1986). Vet. Quart. $8: 257$.

7. Van Reeth, K. and Pensaert, M.B.(1994). Am.J.Vet. Res. (in press).

8. Voets, M.T., Pensaert, M. and Rondhuis, P.R.(1980). Vet.Quart. $2: 211$.

9. Callebaut, P. and Pensaert, M.(1992). Med. Fac. Landbouww. Univ. Gent, 57/4b : 2077.

10. Graham, F.L. and Prevec, L.(1991). Methods Mol. Biol. 7 : 109.

11. Ghosh-Choudhury, G., Haj-Ahmad, Y., Brinkley, P., Rudy, J. and Graham, F.L.(1986) Gene $50: 161$.

12. Zheng, B., Graham, F.L., Johnson, D.C., Hanke, T., McDermott, M.R. and Prevec, L.(1993). Vaccine 11 : 1191 .

13. Graham, F.L. and van der Eb, A.J.(1973). Virology $52: 456$.

14. Callebaut, P. Debouck, P. and Pensaert, M.(1982). Vet. Microbiol. $7: 295$.

15. Tô, L.T. and Bernard, S.(1992). Res.Virol. $143: 241$. 